\title{
Trajetória e avaliação dos programas federais brasileiros voltados a promover a eficiência administrativa e fiscal dos municípios
}

\author{
Eduardo José Grin
}

Escola de Administração de Empresas de São Paulo

\begin{abstract}
O artigo apresenta a trajetória dos programas do governo federal direcionados à modernização administrativa e fiscal dos municípios brasileiros desde os anos 1930. O foco do trabalho, contudo, são os programas implantados nos governos Fernando Henrique Cardoso (1995-2002) e Lula (2003-10) voltados a incrementar as capacidades administrativas e fiscais das cidades. $\mathrm{O}$ argumento central é que esses programas sempre foram concebidos e executados pelas burocracias federais propondo soluções para os municípios que representam a visão "modernizadora" do governo central para os problemas de gestão dos governos locais. Essas iniciativas têm duplicado esforços e não contribuem para enfrentar as carências administrativas municipais, o que limitou seu alcance e gerou poucos resultados desde sua reinserção na agenda do governo federal a partir de 1997.
\end{abstract}

Palavras-chave: municípios; administração; modernização; gestão fiscal; burocracia.

Trayectoria y evaluación de los programas federales brasileños destinados a promover la eficiencia administrativa y fiscal de los municipios

Lo artículo enfoca la trayectoria de los programas del gobierno federal para la modernización administrativa y fiscal de los municipios brasileños desde los años 1930. Lo foco del texto, todavía, son los programas implantados en los gobiernos Fernando Henrique Cardoso (1995-2002) y Lula (2003-10) que intentaran incrementar las capacidades administrativas y fiscales municipales. Lo argumento central es que eses programas siempre fueran concebidos y ejecutados por las burocracias federales proponiendo soluciones para los municipios que representan la visión "modernizante" del gobierno federal para los problemas de gestión de los gobiernos locales. Esas iniciativas duplicaran esfuerzos y no contribuyen para combatir las carencias administrativas municipales, lo que limitó su alcance, además de generar pocos resultados desde su reinserción en la agenda del gobierno federal desde el año 1997.

Palabras clave: municipios; administración; modernización; gestión fiscal; burocracia.

http://dx.doi.org/10.1590/0034-76121399

Artigo recebido em 9 dez. 2012 e aceito em 15 jan. 2014. 
Path and evaluation of Brazilian federal programs aimed at promoting administrative and fiscal efficiency of municipalities

The article deals of the path of programs of federal government dedicated to administrative and fiscal modernization of Brazilian cities since the 30s. The focus in this text, however, is the programs implemented during Fernando Henrique's government (1995-2002) and Lula's government (2003-10) aimed at to increase the administrative and fiscal capacities in the cities. The central argument is about these programs having always been designed and implemented by federal bureaucracies proposing solutions for municipalities that represent the "modernizing" vision of the central government to management problems of local governments. These initiatives have duplicated efforts and don't help to envisage the municipal administrative failures, which limited its reach and generated few results since their return in the agenda of the federal government from 1997.

KEYWORDs: municipalities; administration; modernization; fiscal management; bureaucracy.

\section{Introdução}

Desde 1930, o tema da eficiência administrativa e fiscal municipal tem sido recorrente no federalismo brasileiro e as políticas das elites centrais sempre buscaram integrar as cidades nos esforços de modernização do Estado nacional em novos padrões organizacionais. Este trabalho descreve e analisa a trajetória dessas iniciativas do governo federal. Mesmo priorizando os governos Fernando Henrique Cardoso (1995-2002) e Lula (2003-10), se discute que, com distintos enfoques, essa questão é constante na agenda do governo federal desde a década de 1930. O objetivo do artigo é avaliar a trajetória desses programas e mostrar que foram sempre concebidos pela esfera central visando inserir os municípios no processo de modernização do Estado brasileiro.

Para Vitor Nunes Leal (1978), após o Estado Novo, em 1937, o governo federal buscou controlar e tutelar administrativamente os municípios. ${ }^{1}$ A fiscalização financeira era considerada necessária para inibir a autonomia municipal, vista como demasiada pelo discurso oficial, buscava-se prestar assistência técnica para as cidades adotarem métodos modernos de administração. Após a Constituinte de 1946, que logrou ampliar a autonomia municipal, se reduziram as ações do governo federal nessa direção. Mas o projeto técnico-modernizador se manteve na criação da Associação Brasileira de Municípios (ABM) e na influência da elite burocrática do Departamento Administrativo do Serviço Público (Dasp), Instituto Brasileiro de Geografia e Estatística (IBGE) e Instituto Nacional de Estatística (INE) na agenda do movimento municipalista (Melo, 1993). O municipalismo fomentado pela elite burocrática central compreendia assistência técnica na

\footnotetext{
${ }^{1}$ Segundo Leal (1978:85), para o governo federal, na administração municipal havia "falta de métodos racionais, desorientação administrativa, gestão financeira perdulária, dívidas crescentes (...)”.
} 
ampliação das bases fiscais dos municípios, elaboração de cadastros fiscais, instituição do sistema de mérito na política de pessoal, criação de planos de cargos e salários, racionalização administrativa, organização e métodos na administração municipal, implementação de modernos procedimentos e técnicas de elaboração e controle orçamentário e de prestação de contas (...). (Melo, 1993:93)

Durante o regime militar (1964-85), o Sistema Federal de Planejamento considerava os municípios unidades federativas a quem se deveria prestar assistência administrativa (Rezende, 2009). Esta articulação federativa

ficava a cargo da Secretaria de Assistência a Estados e Municípios (Sarem), criada em 1972 (...) para prestar assistência técnica, elaborar normas sobre a aplicação dos recursos do Fundo de Participação dos Estados e do Fundo de Participação dos Municípios, conforme as prioridades federais, e desenvolver sistemas de informação. (Rezende, 2009:14)

De forma particular,

a concessão, pelo governo federal, de assistência técnica aos municípios na área fazendária já tem uma história. Curiosamente, as iniciativas pioneiras e mais intensas, tendo à frente o Ministério da Fazenda, foram desenvolvidas entre os anos 70 e 80, durante a vigência do sistema tributário anterior, que era fortemente centralizador das receitas e da política tributária. (Afonso et al., 1998:19)

Após 1988, as atribuições municipais se ampliaram com a descentralização de políticas públicas, intensificando o desenvolvimento de suas capacidades institucionais. Para Arretche (1996), a relação entre a esfera federal e os municípios vinha se organizando desde o regime militar. Mas será em 1997, com a criação do Programa de Modernização da Administração Tributária (Pmat), no contexto do que viria a ser a Lei de Responsabilidade Fiscal, que o governo federal retomou o tema da eficiência administrativa e fiscal municipal. Em sua concepção, o Pmat era considerado

uma dessas iniciativas pioneiras do governo federal (...) que vem contribuindo para a ampliação das receitas próprias das prefeituras, o controle dos gastos e a racionalização do uso dos recursos públicos, além da melhoria da qualidade de atendimento ao cidadão e a maior transparência na ação governamental. (Guarneri, 2002:2)

No ano 2001 surgiu o Programa Nacional de Apoio à Gestão Administrativa e Fiscal dos Municípios Brasileiros (PNAFM), ${ }^{2}$ dedicado a aumentar a capacidade de arrecadação munici-

\footnotetext{
${ }^{2}$ Para o Ministério da Fazenda (2002:1) “O (...) PNAFM integra o esforço permanente do Governo Brasileiro no sentido da manutenção da estabilidade social e macroeconômica, e tem por objetivo principal auxiliar os municípios 
pal (Ministério da Fazenda, 2006). Ambos os programas consideravam essa a meta central de eficiência administrativa. Nessa linha se enquadrava o "Simples Municipal" (Guedes, 2001) do governo Fernando Henrique Cardoso-PSDB (1995-2002), doravante FHC, que complementou essa agenda temática do governo federal. Os governos Lula-PT (2003-10) pouco inovaram nessas políticas, pois essencialmente mantiveram os programas existentes para modernizar a gestão municipal.

Para realizar essa análise longitudinal, realizou-se uma pesquisa bibliográfica para organizar a trajetória dos programas. Em seguida procedeu-se a um levantamento de documentos para conhecer a estrutura e os objetivos dos programas. Foram obtidos dados secundários que permitiram analisar os resultados alcançados, sobretudo das iniciativas criadas após 1997. Contudo, diante da escassez de estudos sobre esse tema, esta é uma pesquisa exploratória. Para tanto, o trabalho se orienta pela análise qualitativa de casos historicamente localizados (Ragin 1987; Tilly, 1983). Os programas, portanto, foram compreendidos como unidades de análise historicamente contextualizadas, tomados em sua singularidade, mas comparados para identificar suas similaridades e diferenças.

Além desta introdução, o trabalho possui quatro partes. A primeira, o referencial teórico para analisar os programas. Segue-se discutindo a questão da eficiência administrativa municipal entre 1930 e o final do regime militar. Na terceira seção se analisam as iniciativas dos governos FHC e sua vinculação com a Lei de Responsabilidade Fiscal. Finalmente, se abordam as medidas adotadas nos governos Lula visando modernizar a gestão municipal.

\section{Referencial teórico: capacidades estatais e a trajetória da dependência dos programas}

Segundo Evans, Rueschmeyer e Skocpol (2002), investigar capacidades estatais comumente significa identificar estruturas organizacionais cuja ausência ou presença seja crítica para os governos realizarem certas tarefas. Para os autores, as capacidades fiscal e administrativa são dois dos determinantes para analisar os Estados como organizações. Hacker (1998), por exemplo, afirma que a capacidade administrativa é uma característica institucional que afetou o patrocínio governamental ao seguro-saúde no Canadá, Estados Unidos e Inglaterra. Este argumento pode ser ampliado para outras políticas públicas. Assim, avaliar o estágio das capacidades administrativas pode revelar as prioridades políticas para a construção do Estado. Sobretudo porque a capacidade e a autonomia estatal podem influir na implementação política ao reduzir a oposição de grupos sociais (Skocpol, 2002).

Para essa abordagem, a presença de burocracias bem financiadas e capacitadas é importante, pois são atores que possuem recursos políticos para alcançar fins definidos. Burocracias especializadas e insuladas em relação aos interesses de outros atores formulam e implemen-

brasileiros a melhorar a eficiência e aumentar a transparência de sua gestão administrativa e fiscal”. 
tam políticas. ${ }^{3} \mathrm{O}$ aparato burocrático do Estado possui tal poder, pois combina capacidade administrativa e autonomia para definir e perseguir objetivos políticos. De 1930 em diante, a modernização fiscal e administrativa dos municípios brasileiros é recorrente na agenda do governo federal, sempre concebida e implantada por suas burocracias. Até 1945, por meio do Dasp e seus braços estendidos para os Departamentos de Municipalidades. A seguir, com o "municipalismo pragmático" que pautou a criação da ABM com o apoio das elites burocráticas federais após 1946. No regime militar, com o Ministério do Planejamento (Sarem) e o Ministério da Fazenda. E em 1997 a questão ressurge com as burocracias desses dois ministérios, respectivamente apoiados pelo corpo técnico do Banco Nacional de Desenvolvimento Econômico e Social (BNDES) e da Caixa Econômica Federal (CEF).

Conforme o conceito de autonomia de Skocpol (2002), o governo federal, por meio de suas burocracias especializadas, formulou e implementou essas políticas sem enfrentar oposição ou veto nas arenas federativas. Esta agenda de ação definiu-se de forma centralizada e evitou barganhas e negociações. Diferente das medidas de "imposição de perdas" aos municípios, como a regulamentação das alíquotas do ISS e da taxa de iluminação pública, votadas no Congresso entre 1989 e 2006 (Arretche, 2009), as ações de "assistência técnica" passaram ao largo do parlamento. Mesmo que, segundo Pierson (1993), tais políticas influenciassem nas relações intergovernamentais entre o nível federal e os municípios.

Para Arretche (2012:177), o federalismo brasileiro apresenta como característica uma concentração de autoridade regulatória na União que cria mecanismos institucionais visando à redução das desigualdades territoriais. Some-se ainda uma combinação de histórica centralização no governo federal e autonomia política municipal após 1988. Nesse cenário, segundo a autora, a União exerce papéis regulatórios e de supervisão, por meio de iniciativas de âmbito nacional, com o objetivo de redistribuir recursos entre os entes subnacionais e atenuar a desigualdade territorial entre os governos subnacionais.

Desenvolver políticas específicas reforça a autoridade e as capacidades institucionais das burocracias em áreas-chave como a geração de recursos financeiros. Essa condição é essencial para se atingir objetivos políticos, juntamente com um staff qualificado tecnicamente (Skocpol, 2002). Conforme Kjaer, Hansen e Thomsen (2002:21), "a capacidade para mobilizar receitas fiscais é a linha de base da capacidade estatal", apoiada no sistema administrativo especializado. Ambas as finalidades - administrativa e fiscal — foram constantes nas ações do governo federal voltadas à gestão municipal após 1930, tornando-se mecanismos explicativos da eficiência almejada nas "capacidades estatais".

O período pós-1930 representou uma "conjuntura crítica" (Hacker, 1998; Thelen, 2003), pois o Estado brasileiro realinhou sua forma de desenvolvimento. Nesse processo, a eficiência administrativa municipal era um "problema", nos termos de Kingdon (1997), pois

\footnotetext{
${ }^{3}$ Esta concepção se assemelha à "especificação de alternativas" de políticas em Kingdon (1997), ao se referir aos hidden participants na fase da implementação.
} 
sua falta de racionalidade organizativa e de capacidade fiscal debilitava a Nação. Daí provém a trajetória das políticas federais e suas burocracias especializadas, sobretudo nos Ministérios do Planejamento e da Fazenda. Nos termos de Pierson (1993, 1995) e Thelen (2003), em todo o período posterior a 1930 o percurso das políticas federais de modernização administrativa municipal possui essa path dependence institucional e de objetivos. Mesmo após 1988, como veremos, a esfera federal "modernizadora" continuou a propor soluções fiscais e administrativas aos municípios.

Já os municípios tiveram outra caminhada de aprendizado institucional em relação a essas políticas do governo federal. Com o final do Estado Novo, o municipalismo autônomo foi o contraponto ao modelo centralizador. Após 1946, o mesmo processo político que criou a ABM também instituiu o Instituto Brasileiro de Administração Municipal (Ibam). Durante o regime militar, a centralização administrativa em nível federal reduziu a autonomia municipal, embora se mantivessem ações direcionadas a modernizar a gestão das localidades.

Após 1988, o discurso da autonomia se recolocou apoiado na descentralização de políticas públicas, mas sem iniciativas de modernização fiscal e administrativa, que só voltou à agenda do governo federal em 1997. Mas será visto que os resultados do Pmat e PNAFM são pequenos e que nos municípios não houve, segundo Pierson (1993), um policy feedback (realimentação de políticas) positivo e de aprendizado em relação aos programas federais. Sobretudo em se tratando, segundo esse autor, de transformar capacidades estatais por meio de arranjos administrativos novos ou existentes que, por sua vez, mudam as possibilidades de implementar novas políticas públicas. Na seção seguinte se apresenta a trajetória desses programas até a década de 1990.

\section{A evolução do tema da gestão municipal na agenda do governo federal até 1997}

Segundo Melo (1993:88), “após a Revolução de 30, e particularmente durante o Estado Novo, o municipalismo foi elevado à condição de princípio programático das elites governamentais e de peça importante da estratégia de nation-building perseguida". O objetivo era moralizar a administração municipal e ampliar sua eficiência, justificada para controlar sua autonomia e dependência das máquinas políticas locais na República Velha. Para tanto, em 1937, foram criados os "Departamentos de Municipalidades" vinculados aos interventores estaduais. Esses órgãos tutelavam a vida administrativa e financeira dos municípios fiscalizando orçamentos, prestando assistência técnica e apoiando ações de racionalidade organizacional. A intenção era aperfeiçoar a administração municipal para torná-la mais econômica e produtiva (Leal, 1978). Esta visão ajuda a explicar por que a origem de órgãos federais como o IBGE (1938), o INE (1934) e o Dasp (1938) incentivou o "municipalismo pragmático" na década seguinte (Melo, 1993). Assim, desenvolver as capacidades estatais locais entrou na agenda do governo federal como meio de controle político e administrativo, implementada segundo uma lógica intervencionista e apoiada em ações modernizadoras oriundas do poder central. 
Após o final do governo Vargas (1945), o movimento municipalista ampliou sua articulação criando a ABM em março de 1946. Para Melo (1993), a ABM buscava realizar estudos da organização e métodos de trabalho, disseminar e prestar a assistência técnica, alinhados ao "municipalismo pragmático". A ABM liderou o lobby em favor da autonomia municipal na Constituinte, o que resultou no fim do controle dos interventores na gestão municipal. Contudo, ficou facultado aos estados terem seus órgãos de "assistência técnica" e fiscalização das finanças locais (Leal, 1978), de modo que o controle municipal se manteve como prerrogativa dos governos estaduais.

Nesse contexto não havia apoio do municipalismo a propostas modernizadoras da gestão local advindas do governo federal, pois se temia seu uso político. A solução encontrada pela ABM foi apoiar a criação do Ibam, uma sociedade civil privada, sem apoio oficial, para oferecer assistência técnica aos municípios. Essa foi a resposta contra o centralismo burocrático do governo federal que inibia a modernização local (Melo, 1993). A criação do Ibam, portanto, se inscreve no processo histórico de construção organizacional do Estado brasileiro, iniciada a partir de 1930, e sua proposta de atuação se assemelha à proposta de reforma institucional do Dasp. Mas no caso do Ibam buscou-se compatibilizar, num contexto democrático e descentralizado, uma estratégia de modernização da administração municipal, no âmbito da Federação, por uma instância que não era e não podia ser municipal (Melo, 1993).

Na década de 1960, no governo Jânio Quadros, que era originário do municipalismo, o afastamento crítico da esfera federal se arrefeceu. Foi criado o Serviço Nacional de Assistência Técnica aos Municípios (Senam) para atuar na articulação federativa, desenvolvimento econômico e social e prestar apoio técnico. Após a sua extinção em 1970, foi substituído pela Secretaria de Articulação com os Estados e Municípios (Sarem), criada em 1972, vinculada à Secretaria de Planejamento da Presidência da República (Rezende, 2009; Saddi, 2003). Segundo Rezende (2009), a implantação do Sistema Federal de Planejamento (SFP), em 1972, repôs na agenda federativa a gestão municipal buscando: a) coordenar a elaboração e a execução de programas; b) aplicar critérios técnicos na escolha de prioridades; c) modernizar a administração pública; e d) estabelecer um fluxo permanente de informações. O órgão central do SFP era o Ministério do Planejamento e Coordenação-Geral, a quem cabia articular as ações a cargo dos entes federados. Esse processo ocorria diretamente através das unidades centrais de planejamento, e indiretamente mediante o relacionamento dos órgãos setoriais federais com seus congêneres estaduais e municipais.

A Sarem prestava assistência técnica aos municípios, elaborava normas e coordenava a aplicação de recursos do Fundo de Participação dos Municípios (FPM) conforme as prioridades federais. De 1974 a 1978, por meio do Programa de Cooperação Técnica, a Sarem buscou organizar os Sistemas Estaduais de Planejamento, repassando aos órgãos estaduais poderes para aprovar a aplicação do FPM em municípios com mais de 25 mil habitantes, afora examinar pedidos de operação de crédito vinculados ao FPM (Saddi, 2003). Ao mesmo tempo, segundo Afonso e colaboradores (1998:19), o Ministério da Fazenda prestou assistência técnica federal aos municípios até o final da década de 1980. O destaque foi o Convênio de Incentivos 
ao Aperfeiçoamento Técnico-Administrativo das Pequenas Municipalidades (Ciata), que entre 1973 e 1981 atendeu 769 prefeituras (um quinto do total à época).

A reforma do Estado implementada pelo regime militar, portanto, promoveu ações visando ampliar a eficiência administrativa municipal. Segundo Arretche (1996), pós-1964, a expansão do Estado que fortaleceu as capacidades administrativas de estados e municípios explica em parte a natureza da descentralização encetada no final dos anos 1980. Com efeito, como se lê no Decreto-Lei no 200/1967 (art. 11), a descentralização se deveria "delegar competências para assegurar mais rapidez e objetividade às decisões situadas nas proximidades dos fatos, pessoas ou problemas a atender". Mas a relação do regime militar com os municípios não seguiu essa trajetória, apesar de a "centralização dos poderes na União em detrimento dos governos locais" figurar como uma das causas do chamado "entravamento do serviço público" (Brasil, 1969 apud Brose, 2002).

Os governos Sarney (1985-89) e Collor (1990-92) pouco têm a dizer sobre o tema da modernização administrativa municipal. Nessas gestões houve um desmonte das burocracias federais nos Ministérios do Planejamento e da Fazenda que respondiam por essas iniciativas. Segundo Afonso (1998:20), "a tradição de assistência técnica foi bruscamente interrompida pouco depois de instalado o novo sistema tributário. O marco institucional foi a reforma administrativa do governo Collor, que extinguiu a Secretaria de Economia e Finanças (SEF), do Ministério da Fazenda, dentre outros órgãos”. Esse tema ressurge na metade do primeiro governo FHC, em 1997, com a criação do Pmat, como será discutido a seguir.

\section{A questão da eficiência administrativa municipal nos governos FHC (1995-2002)}

Em agosto de 1997, a Diretoria do BNDES criou o Pmat, lançado pelo Ministério do Planejamento. Até 1999, voltava-se à modernização da administração tributária, financeira e patrimonial. Em maio desse ano, o programa foi alterado para ampliar seus efeitos fiscais. Além da melhoria na qualidade do gasto público e na gestão fiscal, incorporou o aumento da eficiência na saúde, educação e assistência social, passando a denominar-se Programa de Modernização da Administração Tributária e da Gestão dos Setores Sociais Básicos (BNDES, 2009). Na "administração da saúde", priorizou-se a gestão de unidades e de programas de saúde e, na "administração da educação", a gestão de unidades e programas escolares, além do Fundef. Na "administração geral", buscava-se modernizar a gestão de recursos humanos, de contratos, licitações e compras, folha de pagamento e de eficiência energética.

A partir de maio de 2000, já com a Lei Complementar no 101 (Lei de Responsabilidade Fiscal — LRF) em vigor, o Pmat passou a apoiar financeiramente as prefeituras para cumprirem os seus dispositivos. O governo federal passou a considerar a questão fiscal, sobretudo a ampliação da capacidade de arrecadação, o parâmetro central da eficiência administrativa municipal. Argumentava-se que a responsabilidade fiscal geraria uma administração eficiente e uma cidade melhor. Ressalte-se que a coordenação dessas iniciativas foi repassada a um 
banco público (BNDES), em cuja missão consta o apoio à redução das desigualdades regionais. Segundo Guarneri (2002), uma de suas diretrizes estratégicas era apoiar a modernização da gestão pública, notadamente no âmbito municipal. Mas como o BNDES não possui capilaridade nacional, desde o ano 2000, o Banco do Brasil passou a ser a principal porta de entrada dos pequenos municípios.

O programa foi concebido para auxiliar a implantação da LRF nas municipalidades: pelo art. 64, a União deveria prestar assistência técnica para os municípios modernizarem sua administração tributária, financeira, patrimonial e previdenciária. Conforme esse artigo, se previa a instalação de um Conselho de Gestão Fiscal com representantes de todas as esferas de governo para disseminar práticas que busquem maior eficiência e alocação do gasto público. Esse fórum deveria instituir premiação e reconhecimento público aos titulares dos poderes que obtivessem avanços no desenvolvimento social, conjugados à boa gestão fiscal. Uma lei deveria definir a composição e o funcionamento do Conselho e nunca foi regulamentada. Possivelmente, até o momento, o nível central tenha demonstrado pouco interesse em criar uma instância que pode gerar conflitos no trato da gestão fiscal municipal.

Esta cooperação compreendia o financiamento de bancos públicos e o cumprimento da LRF tornou-se fundamental para modernizar administrativamente as prefeituras (Guedes, 2001; Corrêa, 2009). Nessa linha, o governo federal lançou, em maio de 2000, o "Simples Municipal". Este esforço foi coordenado pelo Ministério do Planejamento/BNDES e contou com a participação de entidades da sociedade civil como: Escola de Administração de Empresas de São Paulo, Instituto Ruy Barbosa/São Paulo, Instituto de Estudos, Formação e Assessoria em Políticas Sociais (Polis/São Paulo), Tribunal de Contas do Estado do Rio Grande do Sul e especialistas em finanças e previdência públicas.

O resultado dessa ação coletiva foi a proposição de "um conjunto de ações voltadas especialmente para Prefeituras de pequeno porte e do interior, visando facilitar a administração das suas contas e assegurar a implantação de um novo regime fiscal responsável". O "Simples Municipal" foi publicado nos Cadernos Ibam e patrocinado pelo BNDES, objetivando auxiliar a "gestão eficiente e responsável da coisa pública, meta perfeitamente alcançável por todos os governos locais, e que contribui para a Reforma do Estado". Por isso, o Banco entendia que era uma instituição estratégica na política econômica de longo prazo e, ao mesmo tempo, central para reformular o Estado em todos os níveis da Federação.

A rigor, a política fiscal era compreendida como o ápice do planejamento municipal (Guedes, 2001). Inclusive, foi vista como condição necessária e suficiente para aumentar a autonomia municipal, pois ampliaria as capacidades de arrecadação própria e reduziria a dependência das transferências federais. Esta consideração está em linha com Guarneri (2002:19), quando afirma que o Pmat é "um instrumento de política pública voltada para o aumento da capacidade de governo em diferentes áreas da gestão local".

Quanto às normas operacionais, definidas pela burocracia técnica do BNDES, o programa estipula um prazo de financiamento de oito anos, já incluída a carência máxima de dois anos. Em tese, isso estimularia os prefeitos a assumirem o empréstimo e passar a conta ao seu sucessor. Mas tem ocorrido o contrário: devido ao tempo para analisar os projetos e liberar os 
recursos, os prefeitos gastam boa parte dos mandatos buscando obter o financiamento e seu sucessor acaba assumindo com o dinheiro em caixa. Possivelmente este é um dos desincentivos do programa que podem ter contribuído para que a adesão voluntária dos municípios tenha sido muito pequena desde 1997, como veremos.

Além disso, as exigências legais e administrativas para os municípios também desestimulam a adesão ao programa. Requerem-se certidões negativas de débito com relação a tributos federais, dívida ativa da União e os Certificados de Regularidade Previdenciária e do FGTS. Deve-se ter a comprovação do adimplemento junto ao Sistema Financeiro Nacional para o Ministério da Fazenda autorizar a operação de crédito e os limites que podem ser comprometidos, conforme os arts. 32 e 33 da LRF. Após essa etapa, o município deve apresentar bens oferecidos em garantia, série histórica de projeção da receita e do comprometimento do fundo ou tributo a ser vinculado como reserva de pagamento. Uma das garantias são as cotas-parte do Fundo de Participação dos Municípios (FPM) e/ou receitas provenientes do ICMS ou ICMS-Exportação. Tais contingenciamentos ainda devem incorporar a previsão de impacto no gasto público como decorrência da implantação do programa e a expectativa de aumento na arrecadação própria. No município, deve-se verificar se a Lei Orgânica prevê a contratação de operações de crédito e, caso positivo, o prefeito necessita aprovar uma lei autorizativa na Câmara Municipal para contratar o financiamento. Por fim, o financiamento deve ser aprovado pelo Senado Federal que, desde 1946, possui essa prerrogativa em relação aos municípios.

Essas exigências legais e políticas possivelmente reduzem o interesse dos municípios no Pmat. O fluxo de análise é demorado, sobretudo para pequenas cidades que acessam o programa via Banco do Brasil local, intermediário do BNDES. Ademais, as demandas iniciais já promovem ajustes nas contas municipais ao exigirem adimplência junto ao governo federal. O município ainda precisa apresentar garantias que podem comprometer suas transferências futuras de FPM, sem a certeza de ser exitoso na redução da despesa e ampliação de receitas próprias. Por fim, precisa se submeter às duas arenas legislativas (uma federal e outra local), o que pode criar dificuldades na negociação e barganha com esses atores, além de não controlar os prazos de aprovação, sobretudo no Senado. Como essa situação é pior para os municípios menores e mais dependentes de recursos do FPM, a adesão do Pmat tem ocorrido em capitais e cidades de maior porte. Estas têm relação direta com o BNDES, melhor situação fiscal, maior capacidade de arrecadação e menor dependência das transferências do FPM. Portanto, o programa gerou uma assimetria de acesso que acabou prejudicando as localidades com menor capacidade técnica e fiscal.

Segundo Guarneri (2002), até maio desse ano, havia 39 operações contratadas e 79 aprovadas, sendo $77 \%$ na administração tributária e $16 \%$ na saúde, educação e assistência social. O Banco do Brasil, que atendia os pequenos municípios, tinha, nesse período, quatro operações contratadas e 33 aprovadas. Das localidades atendidas pelo BNDES, 74\% eram municípios com mais de 100 mil habitantes e no Banco do Brasil 68\% tinham até 50 mil habitantes. Das 39 cidades atendidas pelo BNDES, 13 eram capitais e boa parte do restante eram cidades de médio porte, sobretudo no estado de São Paulo (15 municípios), cujas capacidades administrativas eram maiores em relação às pequenas localidades. 
Outra iniciativa do governo federal para ampliar a eficiência administrativa municipal foi o PNAFM, criado em 1999 no âmbito do Ministério da Fazenda. Em 1996, o Banco Interamericano de Desenvolvimento (BID) aprovou empréstimo de US\$ 500 milhões ao Brasil, em apoio à modernização fiscal do Distrito Federal e dos estados brasileiros: Programa Nacional de Apoio à Administração Fiscal para os Estados Brasileiros (Pnafe). Em 2001, um novo empréstimo do governo brasileiro junto ao BID financiou o PNAFM (Ministério da Fazenda, 2010). Sua operação iniciou-se em 2001, mas como no ano seguinte apenas cinco cidades o contrataram, ${ }^{4}$ sua avaliação será realizada na próxima seção que discute os governos Lula (2003-10). Abaixo segue a apresentação do programa formulado entre 1996 e 1999 na gestão FHC.

O PNAFM foi concebido para integrar o esforço de estabilidade macroeconômica das contas públicas nacionais. Seu objetivo é auxiliar os municípios a melhorar sua gestão administrativa e fiscal e elevar a proporção do gasto público apoiada em receitas próprias. Isso ampliaria a autonomia para financiar os gastos públicos, seria uma medida administrativa e contribuiria para os municípios cumprirem a LRF. O órgão executor é a Unidade de Coordenação de Programas (UCP) da Secretaria Executiva do Ministério da Fazenda. Para descentralizá-lo até o nível municipal, a CEF atua como agente financeiro e coexecutora (Ministério da Fazenda, 2006). Suas operações iniciaram com US\$2,2 bilhões, sendo 50\% financiados pelo BID e 50\% como contrapartida da União (2\%) e prefeituras (48\%). Este valor era considerado suficiente para modernizar a gestão administrativa ${ }^{5}$ e fiscal ${ }^{6}$ da totalidade dos municípios.

Pela falta de capilaridade territorial do Ministério da Fazenda, a execução coube à CEF para: a) receber a Carta de Intenção do município; b) orientar sobre o programa e o Termo de Adesão a ser assinado pelas autoridades municipais; c) prestar assistência técnica com as Gerências de Desenvolvimento Urbano na elaboração dos projetos; d) auxiliar a Unidade Executora Municipal (UEM) na fase inicial de operação das atividades do programa. Como o Pmat, a assessoria técnica visando ampliar as capacidades administrativas municipais foi assumida por um banco público.

As condições de aprovação do empréstimo são similares ao Pmat, inclusive a aprovação na Câmara Municipal e no Senado Federal, acrescida da ratificação do BID. Os municípios passam por três arenas burocráticas (Ministério da Fazenda/UCP, Secretaria do Tesouro Nacional e BID) e duas arenas políticas (uma local, outra federal). Quatro anos é o período de execução do programa, há carência de mais quatro anos para iniciar o pagamento, incluídos os juros, e 16 anos de prazo de amortização, sendo o saldo devedor atualizado pela variação

\footnotetext{
${ }^{4}$ Salvador (BA), Santa Maria (RS), Santa Luzia (MG), Ribeirão Pires (SP) e Maceió (AL).

${ }^{5}$ Inclui a implantação do Plano Diretor, Programa de Educação Fiscal, implantação e revisão de Plano de Cargos e Salários, Programas de Capacitação, adequação de ambientes, implantação de ouvidoria e instalação de centrais de atendimento.

${ }^{6}$ Elaboração do cadastro de contribuintes, melhoria de arrecadação e cobrança, fiscalização e controle dos débitos da dívida ativa, ações para melhorar a elaboração e acompanhamento do orçamento, programação financeira, contabilidade e auditoria.
} 
cambial. São aceitas contrapartidas econômicas e não apenas financeiras, como investimentos básicos realizados em capacitação, desde que alinhados à finalidade do projeto, segundo a Cartilha PNAFM apresentada pela Caixa Econômica Federal (<http://downloads.caixa.gov. br/gov/cartilhapnafm.pdf $>$ ). Esta foi a configuração do programa até o final de 2002. A seguir se discute a eficiência administrativa municipal nos governos Lula, iniciando com a implementação do PNAFM.

\section{A questão da eficiência administrativa municipal nos governos Lula (2003-10)}

Os dois governos Lula inovaram pouco nos programas dedicados à eficiência e capacidade administrativa municipal, pois houve mais mudanças incrementais em relação às iniciativas existentes. Ainda assim, no final dessa seção, apresentam-se outras ações que, nesse período, apoiaram a modernização da gestão municipal, apesar da sua tímida implementação. Inicia-se avaliando o PNAFM, considerando sua apresentação anterior.

Este programa também tem apresentado um desempenho fraco em termos de adesão municipal. Suas regras operacionais, mesmo com 16 anos para amortizar o empréstimo, não incentivam sua contratação. As razões são similares àquelas discutidas no caso do Pmat: fluxo demorado de análise (o Ministério da Fazenda e a CEF divulgam que, após a Carta de Interesse ser entregue, o prazo máximo para liberar os recursos na conta da Prefeitura seja 180 dias). Este período dificilmente é cumprido, pois, dentre as dificuldades para elaborar os projetos, segundo o Ministério da Fazenda (2006), estão duas causas centrais: a) baixa qualidade técnica dos municípios para preparar propostas, pois as exigências operacionais são incompatíveis com seu nível de maturidade gerencial; b) baixa capacidade organizacional, tecnológica e de recursos humanos no próprio Ministério da Fazenda. Ademais, há falta de garantias dos municípios e/ou a demora em repactuar as dívidas municipais com a União. Assim, o efeito que deveria ser suprido - a falta de capacidades administrativas e fiscais locais — acaba sendo considerado uma das causas centrais do baixo desempenho do programa, seis anos após o início das operações.

Some-se a essa situação o tempo de análise técnica na Unidade de Coordenação de Projetos (UCP) do Ministério da Fazenda, na Secretaria do Tesouro Nacional e no BID, geralmente seguidos de solicitações de ajustes no projeto. O alongamento dos prazos consome boa parte do período de governo para elaborar o projeto e aprovar o empréstimo, o que dificulta sua utilização. Afora as garantias exigidas, que podem comprometer as receitas municipais, somadas às dúvidas sobre êxito nos resultados. Por fim, considere-se que o BID exige que aquisições acima de US\$200 mil sejam por concorrência internacional, o que retira flexibilidade na utilização dos recursos e amplia os prazos de contratação e pendências licitatórias.

Assim, o prefeito bem-sucedido na obtenção do empréstimo geralmente deixa os recursos disponíveis para seu sucessor, agravado pela possibilidade de ser de um partido e/ou candidato adversário. No Relatório de Acompanhamento do programa em 2006 sublinha-se que o ano anterior, o primeiro dos prefeitos eleitos em 2004, fora marcado por uma revisão 
de projetos em face da redefinição de prioridades das novas gestões, especialmente na área fazendária e de administração. Mas ainda que o prefeito consiga liberar e utilizar os recursos, as parcelas são depositadas na conta do município de forma gradual e com base no cronograma de serviços e aquisições aprovado pelo BID.

É possível que as amarras do programa gerem baixos incentivos à adesão municipal e sejam indicadores de seu fraco desempenho. Até 2007, do montante de recursos disponíveis, o desembolso tinha sido de 10,6\% do total (Ministério da Fazenda, 2007). Para a UCP, que coordena o programa, além da burocracia existente, há falta de técnicos qualificados nessa unidade, assim como na CEF que executa a interface operacional com os municípios. Ademais, a postura tem sido mais passiva para aguardar a procura dos municípios do que proativa visando ampliar a adesão de cidades. Nesse ano, em face dessa situação, ajustou-se com o BID o Plano de Aceleração da Execução buscando melhorar o desempenho do programa, sobretudo o fluxo de desembolsos e a eficiência das aquisições. Também se buscou fortalecer atividades de Gestão de Conhecimento e a formação de Redes de Aprendizagem entre municípios. Contudo, como veremos, os resultados foram pequenos.

Além disso, o programa começou a redefinir seu público-alvo buscando os maiores municípios (versão ampliada), em detrimento dos menores (versão simplificada, que deveria ser compartilhada com o BNDES). Segundo Ministério da Fazenda (2006), as cidades com até 50 mil habitantes não obtiveram o resultado desejado em termos de adesão, e nos contratos em andamento apresentavam um ritmo de execução aquém do esperado. De forma geral:

Uma síntese das dificuldades reportadas permite identificar problemas relacionados a 4 fatores causais: (1) pessoas, abrangendo o dimensionamento insuficiente das equipes, o baixo comprometimento dos escalões estratégicos com a implementação do Programa, assim como a falta de capacitação e de experiência em gerenciamento de projetos; (2) processos operacionais complexos, incompatíveis com o estágio de maturidade das equipes locais; (3) sistemas deficientes, principalmente devido à pouca integração e infraestrutura de equipamentos; e (4) problemas externos, decorrentes da mudança de gestão e transição política/administrativa, causando falta de apoio às equipes das UEM. (Ministério da Fazenda, 2006:41)

Tal situação pode ter motivado uma revisão da estratégia do programa visando, segundo o Ministério da Fazenda (2007), atender aos municípios com maior capacidade institucional. Esse Ministério considerou tais questões como vantagens da nova fase do programa, pois se ampliaram as contratações em capitais ou cidades de médio porte dotadas de maiores recursos organizacionais e capazes de arcar com despesas prévias. Portanto, assim como o Pmat, essa nova estratégia do PNAFM aprofundou as assimetrias de acesso entre os municípios grandes e médios e aqueles como menos de 50 mil habitantes. ${ }^{7}$ Em 2007, havia 15 capitais ou

\footnotetext{
${ }^{7}$ Municípios com até 50 mil habitantes representavam, segundo o Censo de 2010, 89\% do total dos 5.565 existentes do país e correspondiam a 45,3\% da população brasileira.
} 
grandes cidades que contrataram o programa, e sete delas representavam $58 \%$ do total dos valores. Concentraram-se os recursos em localidades com melhor capacidade de pagamento dos valores emprestados pelo BID, apesar de menos carentes em termos de capacidades administrativas. O problema da assimetria de acesso se amplia quando os municípios maiores se beneficiaram tanto do Pmat quanto do PNAFM e a grande maioria das pequenas cidades não acessou nenhum dos dois programas.

A primeira fase do programa foi concluída em 2008, e mesmo diante da avaliação do Ministério da Fazenda de seus problemas operacionais, seu desempenho se manteve fraco. Até o final desse ano houve 86 operações contratadas: 61 na modalidade ampliada para atender as capitais e municípios de médio porte e 25 na versão simplificada voltada aos pequenos municípios (CEF, 2008). Os valores em dólares, cerca da US\$ 220 milhões, representavam pouco mais de $10 \%$ do montante total previsto em 2002, ano inicial da sua operação, e atendiam apenas a 1,55\% dos municípios. Dos recursos disponibilizados, as cidades nos estados de São Paulo, Minas Gerais, Rio Grande do Sul, Santa Catarina, Paraná e Rio de Janeiro respondiam por $52,5 \%$. Nos demais estados, excetuado o caso mineiro, são mais 14 capitais. Existiam 46 operações (75\% do total) concentradas em seis unidades da Federação, e nos estados do Norte, Nordeste e Centro-Oeste apenas nas capitais e cidades de maior capacidade fiscal. Até o final de 2010, apenas mais cinco municípios contrataram esse programa, totalizando 91 cidades (1,64\% dos 5.565 municípios brasileiros em 2011). Com efeito, o desempenho do PNFAM nos governos Lula foi muito pequeno.

Até o final de 2008, na modalidade PNAFM ampliado, 61 cidades contrataram financiamentos na modalidade ampliada no valor de $\mathrm{R} \$ 509.441 .173,00$, enquanto 25 pequenas localidades correspondiam a $\mathrm{R} \$ 6.069 .498,00$. Mesmo que a comparação pelo porte populacional possa não ser o melhor parâmetro, pois desconsidera indicadores como o PIB per capita ou IDH-M, ainda assim o volume de empréstimos das cidades com até 50 mil habitantes correspondeu a 1,2\% do total contratado pelas maiores! Esse é mais um indicador da assimetria de acesso ao PNAFM em relação à modernização administrativa dos menores municípios, pois em termos absolutos e proporcionais priorizou recursos às capitais e grandes cidades. Embora as cidades com até 50 mil habitantes representassem 89\% do total no Brasil, conforme o Censo Demográfico de 2010, o desempenho desse programa mostra que esse porte de município representava $29 \%$ das localidades que o contrataram.

Essa situação talvez esteja na base da revisão do acordo firmado entre o Ministério da Fazenda e a CEF, em maio de 2010, para aperfeiçoar os mecanismos de gestão e execução desse programa. Em especial, integrá-lo com outras ações estratégicas do governo federal "voltadas à modernização da gestão municipal". Nesse acordo, a CEF é considerada o principal agente de políticas públicas e assistência técnica do governo federal, além de agente financeiro e coexecutor do programa. Dentre as mudanças pretendidas estão sensibilizar e capacitar os municípios para aderirem ao PNAFM e "fomentar a necessária modernização administrativa e fiscal dos municípios, de forma eficiente, eficaz e efetiva". Mas, a depender dos fracos resultados obtidos até 2010, há um longo processo para se atingir os objetivos de capacitar administrativamente os municípios por meio desse programa. 
Não muito diferentes foram os resultados dos governos Lula com relação ao Pmat. Embora em 2009 o programa atendesse a 369 municípios em todas as regiões do Brasil (apenas cinco estados não possuíam municípios com operações contratadas), persistia um baixo número de adesões e o problema da assimetria no acesso. Nesse ano, desse conjunto de municípios com contratos, 73,4\% estava em São Paulo, Minas Gerais, Santa Catarina, Rio Grande do Sul, Rio de Janeiro e Paraná. Apenas São Paulo concentrava 30,3\% da carteira total de cidades. Já nas regiões Norte e Nordeste, os estados de Amazonas, Maranhão, Paraíba, Tocantins, Roraima, Amapá, Rio Grande do Norte, Alagoas e Sergipe respondiam por 3,8\% das localidades com contratos, afora sua concentração nas capitais. Em relação ao volume de desembolsos, que até o final de 2009 foi de R\$ 751,5 milhões, a assimetria regional é ainda maior: 79,6\% se concentram nos seis estados acima referidos e São Paulo responde por 43,1\% desse montante (cerca de R\$ 324 milhões) (Corrêa, 2009).

Ainda segundo Corrêa (2009), em termos populacionais, os municípios da região Sudeste atendidos pelo Pmat superam a soma de habitantes das cidades de todas as demais regiões. Mas a autora lembra que alguns municípios, sobretudo da região Norte, concentram grande parte da população do estado. "Um exemplo é Manaus, único município do Estado do Amazonas que fez o PMAT. Esse município sozinho representa 51,11\% da população do estado" (Corrêa, 2009:220).

Embora o sítio do BNDES (14-8-2007) destacasse que na carteira ativa do Pmat 53\% fossem operações com até 50 mil habitantes, ainda assim há o problema da assimetria de acesso, pois: a) em termos proporcionais, essas localidades representam 89\% dos municípios brasileiros pelo Censo Demográfico de 2010; b) em termos absolutos, são números pequenos, considerando que o programa opera desde 1997 e se cotejam suas adesões diante do total de municípios existentes no Brasil. Após 13 anos de operação, os 369 municípios representavam apenas 6,63\% dos 5.565 existentes em 2011.

Apesar de mudanças operacionais para ampliar sua cobertura nacional, como a criação em 2008 do Pmat Especial para cidades com até 50 mil habitantes, e acordos com outros agentes financeiros, além do Banco do Brasil, sua performance é fraca. Os incentivos para obter a adesão de municípios têm sido pouco eficazes, como reconhece a Presidência da República (2008:29), pois são sempre os "mais frágeis que são historicamente excluídos dos programas de modernização administrativa". Talvez essa realidade tenha movido os governos Lula em direção a outras iniciativas para melhorar as capacidades administrativas municipais.

Das demais propostas para a gestão municipal destaque-se o Comitê de Articulação Federativa (CAF). Esse fórum foi instituído por um protocolo de cooperação com as entidades nacionais de representação municipal (Associação Brasileira de Municípios, Confederação Nacional de Municípios e Frente Nacional de Prefeitos). Em 2007 foi formalmente reconhecido como instância da Secretaria de Relações Institucionais da Casa Civil. Dele participam 18 ministérios cujas políticas impactam os municípios e 18 representantes das três entidades municipalistas. Dentre seus objetivos está "sugerir procedimentos que promovam a integração das ações, no âmbito da administração pública federal, voltadas ao fortalecimento da capacidade financeira, técnica e gerencial dos governos municipais". 
Um dos grupos de trabalho do CAF, formado em junho de 2007, e assessorado pelos Ministérios da Fazenda e do Planejamento, é o GT Interfederativo, que busca integrar os atores envolvidos no fomento às ações de fortalecimento institucional e qualificação da gestão municipal, desenvolver assistência técnica e simplificar acesso aos programas federais. Sobretudo, responder ao quadro de fragilidade institucional dos municípios e à falta de qualidade na gestão pública para promover a arrecadação de tributos e modernizar a estrutura administrativa e fiscal (Presidência da República, 2010). Contudo, o Pmat e o PNAFM continuaram com seu desempenho pequeno se comparados à demanda dos municípios brasileiros, notadamente as excluídas localidades menores.

Outra iniciativa do GT Interfederativo foi um estudo que agrupou os municípios segundo características comuns de capacidade gerencial. Este trabalho embasou a "Agenda Nacional de Apoio à Gestão dos Municípios" voltada a aumentar as capacidades institucionais locais. De modo geral, o objetivo é fortalecer o Estado brasileiro com o desenvolvimento das capacidades administrativas municipais. Conforme Melo (1993), parece ser uma estratégia de inserir os municípios do projeto de nation building (construção da nação). Da mesma forma, essa concepção se alinha com a Presidência da República (2008:18) quando frisa que o PNAFM está "relacionado à estratégia do Governo Federal para a consolidação e o aperfeiçoamento do pacto federativo constitucional, buscando o fortalecimento institucional dos órgãos responsáveis pela gestão administrativa e fiscal dos municípios brasileiros". Mas o discurso oficial precisa ser mais bem analisado, pois de concreto as ações centrais do governo federal continuam a ser ancoradas nas operações de crédito do Pmat e do PNAFM. Ambos, a despeito das iniciativas no âmbito do CAF, ainda não criaram estímulos para ampliar a adesão dos municípios e romper com a trajetória de exclusão das pequenas cidades. Nessa linha, seguem os comentários finais que podem servir para novas pesquisas.

\section{Considerações finais}

Este trabalho discutiu as ações do governo federal que, desde 1930, buscaram ampliar a eficiência administrativa municipal. Mais especificamente, a análise se concentrou nas gestões FHC (1995-2002) e Lula (2003-10), e a conclusão será realizada considerando as ações desses dois governos.

Desde 1997, o governo federal reinseriu em sua agenda políticas de modernização da gestão municipal. Até 2007, pelo menos seis iniciativas da burocracia federal (Pmat/BNDES/ Ministério do Planejamento, PNAFM/Ministério da Fazenda/Caixa Econômica Federal, somados ao CAF/Casa Civil, Gespublica, Prodev, Brasil Municípios e Cooperação Espanhola no Ministério do Planejamento) foram concebidas com essa finalidade. Esta situação se assemelha ao que Thelen (2003) e Mahoney e Thelen (2010) chamam de institucional layering (estratificação institucional) na evolução dos programas. As políticas federais dedicadas à eficiência administrativa municipal conservaram as existentes, mas se criaram outras em distintos níveis da burocracia. Estas políticas foram, segundo os autores, flexíveis e adaptáveis para serem 
inovadas, mas indicam que as estruturas preexistentes eram fortes para se manterem, mesmo que nenhuma tenha apresentado resultados positivos em sua trajetória. Conforme Thelen (2003:226), as políticas federais "não pressionaram o desenvolvimento posterior ao longo da mesma trilha, como sugerido pelos argumentos dos retornos crescentes".

Conforme Pierson (1993), não houve um policy feedback positivo que fizesse as políticas prévias seguirem uma trajetória de reforço, pois se replicaram iniciativas com objetivos e públicos similares. As escolhas de ambos os programas federais não criaram "pontes" para aproximar suas políticas. Considerando a trajetória das ações desde a década de 1970, os arranjos institucionais existentes nos Ministérios da Fazenda e do Planejamento mantiveram suas iniciativas particulares por meio do PNAFM e do Pmat. Nos termos de Pierson, possivelmente se gerou uma solução coletiva subótima em seus resultados ao se fragmentarem as ações federais voltadas para os mesmos públicos e com finalidades similares.

A duplicidade de programas federais direcionados à eficiência administrativa municipal não tem sido condição suficiente para incentivar as burocracias federais a concentrarem esforços. A esse respeito, veja-se o edital para contratar a consultoria do Programa de Estratégia e Plano de Ação para a Efetividade do Desenvolvimento no Brasil que identifica a sobreposição da ações federais visando a criar "capacidades municipais para a gestão por resultados":

Em apoio às administrações municipais, o governo federal tem desenvolvido uma série de iniciativas no âmbito das políticas de gestão pública e das políticas setoriais, muito embora essas iniciativas caracterizem-se pela sua heterogeneidade, com variedade de forma e conteúdo, e desarticulação, estando dispersas pelos vários órgãos e entidades federais. A desarticulação dos projetos de apoio à melhoria da gestão das políticas públicas em nível municipal resulta em intervenções pontuais, discricionárias, eventualmente sobrepostas e pouco efetivas na construção de capacidades, com baixa efetividade da aplicação de recursos na solução do problema a que se destinam. (...). Fica evidente, portanto, que a ação do Poder Executivo Federal de apoio ao processo de fortalecimento da capacidade de gestão dos municípios deve ser aperfeiçoada, especialmente no que se refere ao modus operandi dos órgãos (...). (Ministério do Planejamento, 2010:3)

Nem mesmo o discurso do governo federal que, desde 2003, incluiu a preocupação com as capacidades locais de gestão em face da descentralização de políticas públicas conduziu a uma maior aproximação dos programas ofertados pela "burocracia especializada".

Transcorridos mais de 20 anos do início da descentralização de políticas públicas para os municípios, já foram discutidas as dificuldades desse processo (Arretche, 1996, 1999; Souza, 2005). Mas esse debate não tem sido acompanhado pelo desempenho dos programas federais voltados a ampliar a eficiência administrativa e fiscal municipal. $\mathrm{O}$ artigo argumentou que faltam estratégias de indução eficientes que estimulem os municípios a aderirem ao Pmat e ao PNAFM. Mais ainda, é pouco provável que os municípios, notadamente os menores, reúnam condições de autonomamente melhorarem sua eficiência administrativa e fiscal. 
Como já frisado, os programas federais têm aumentado a assimetria de acesso ao favorecer que capitais e municípios de maior porte obtenham financiamentos dos bancos públicos. Vale lembrar que, pelo Censo de 2010, 89\% dos municípios brasileiros possuem até 50 mil habitantes e respondem por $45,3 \%$ da população nacional. E essas localidades, conforme a Secretaria do Tesouro Nacional, na evolução da receita bruta municipal entre 1998-2007, representavam 27,2\% do total. Em síntese: há demanda para o Pmat e o PNAFM, ainda que estejam desconectados da realidade municipal brasileira.

Portanto, em face dessa desigualdade federativa, faz sentido sugestões, como a de Vignoli (2009), de que o Ministério do Planejamento deve apoiar municípios com até 30 mil habitantes $(81,5 \%$ do total) sem contrapartidas financeiras. Especialmente se confrontado o desempenho reduzido dos programas oficiais pela dificuldade de os pequenos municípios cumprirem as exigências legais e técnicas para acessarem os financiamentos. Ademais, descentralização de políticas e ajuste fiscal nos municípios não é uma pauta excludente. Assim, seria importante que o governo federal criasse incentivos mais eficazes para desenvolver capacidades administrativas municipais, combinadas àquelas já existentes no âmbito das políticas setoriais descentralizadas.

Mas parece que a ação do governo federal como indutor da reforma do Estado, e sua relação com o federalismo, ainda está distante de incluir o tema da eficiência administrativa municipal em sua agenda. Segundo Barreto, Delgado e Oliveira Júnior (2001), a reconcentração fiscal na União amplia a dependência do poder local de recursos oriundos das instâncias centrais. E a falta desses acaba motivando a guerra fiscal que Melo (1996) chamou de "hobbesianismo municipal". Esta dinâmica não está longe da análise de Pierson (1995:458) sobre o federalismo: "as relações intergovernamentais requerem uma complexa mistura de competição, cooperação e acomodação". Trazido para o tema da eficiência administrativa e fiscal municipal no Brasil: a competição entre cidades é uma realidade; a cooperação federal é ineficaz e acomodam-se as desigualdades nas capacidades institucionais entre as cidades com o apoio dos programas do governo central. Basta lembrar o número, regiões e porte dos municípios que acessaram o Pmat e PNAFM (ambos possuíam 468 operações até o final de 2010, pois algumas cidades tinham os dois financiamentos). Mas mesmo que esse número dissesse respeito ao total de municípios que contrataram um ou outro programa, ainda assim representaria apenas 8,23\% dos 5.565 municípios brasileiros.

Se o discurso de capacidades administrativas e fiscais visando ampliar a autonomia dos municípios importa para o governo federal, a estratégia adotada desde 1997 não evidencia isso. Assim, por exemplo, é inócuo o discurso do governo Lula de que em um:

elevado número de municípios a maior parte (...) depende quase exclusivamente de transferências federais para sua sobrevivência [e tem] baixa arrecadação própria. Portanto, não são capazes de exercer sua autonomia federativa, reconhecida na Constituição. Aprimorar a gestão pública é colocar em prática a autonomia. (Presidência da República, 2008:7) 
Inclusive, ações concorrentes no BNDES/Banco do Brasil e no Ministério da Fazenda/ CEF têm diluído forças. A existência de programas com finalidades idênticas aprofundou ainda mais a desigualdade entre os municípios, visto que apenas os maiores conseguem obter os empréstimos. Contudo, uma vez que o BNDES se vê como promotor da reforma do Estado com o Pmat e a CEF quer fazer do PNAFM o "principal instrumento do governo para fortalecimento da gestão administrativa e fiscal", o caminho da competição entre as burocracias federais parece sobrepor-se ao da cooperação.

Se em políticas nacionais de saúde e educação a União criou mecanismos institucionais que reduziram as desigualdades regionais, no caso do Pmat e do PNAFM não se gerou uma redistribuição de recursos em favor dos municípios menos capacitados. Nesse caso, o papel regulatório da União ampliou, em termos absolutos e relativos, as assimetrias de acesso entre pequenas e grandes cidades. Nessa arena de políticas federais, o desafio de equacionar as desigualdades territoriais em termos de capacidade estatal está a exigir uma revisão de seus mecanismos institucionais.

Assim, se esses dois programas podem servir de estímulo às burocracias federais que respondem pela sua implementação, nos municípios o policy feedback tem sido pequeno, como se verificou pelo reduzido número de projetos contratados em relação ao total de cidades brasileiras. Segundo Pierson (1993), o legado institucional pode pesar fortemente em proposições de mudança. Em particular quando a fragmentação da expertise das burocracias influencia as bases sobre as quais se constroem capacidade e responsabilidades governamentais. Nesse sentido, é importante considerar que:

Nós necessitamos de investigações comparadas de quando e como estruturas estatais estabelecidas, especialmente seus arranjos administrativos e fiscais, são reorganizadas e com quais efeitos sobre as capacidades de produção de políticas (...). Em episódios quando tais esforços deliberados de reforma ou reorganização são feitos dentro de estruturas de estado solidamente estabelecidas, pode ser recompensador estudá-las não apenas pelo seu sucesso em realizar os objetivos declarados (...), mas por suas falhas e consequências não pretendidas. (Evans, Rueschmeyer e Skocpol, 2002:361; tradução do autor).

A modernização da eficiência administrativa e fiscal dos municípios brasileiros promovida pelo governo federal pode ser um bom caminho para seguir essa trilha de pesquisa.

\section{Referências}

AFONSO, José R. et al. Municípios, arrecadação e administração tributária: quebrando tabus. Revista do BNDES, n. 10, p. 1-37, dez. 1998.

ARRETCHE, Marta T. S. Continuidades e descontinuidades da federação brasileira: de como 1988 facilitou 1995. Dados, Rio de Janeiro, v. 52, n. 2, p. 377-423, jun. 2009. 
ARRETCHE, Marta T. S. Democracia, centralização e federalismo no Brasil. Rio de Janeiro: Editora FGV; Editora Fiocruz, 2012.

ARRETCHE, Marta T. S. Mitos da descentralização: mais democracia e eficiência nas políticas públicas. Revista Brasileira de Ciências Sociais, São Paulo, v. 11, n. 31, p. 44-66, jun. 1996.

ARRETCHE, Marta T. S. Políticas sociais no Brasil: descentralização em um estado federativo. Revista Brasileira de Ciências Sociais, São Paulo, v. 14, n. 40, p. 111-141, jun. 1999.

BANCO NACIONAL DE DESENVOLVIMENTO SOCIAL (BNDES). Guia de operações com o mandatário. Rio de Janeiro: BNDES, 2009.

BARRETO, Helena M. S.; DELGADO, Ignacio J. G.; OLIVEIRA JÚNIOR, Lourival B. Os municípios brasileiros e a reforma administrativa. 2001. Disponível em: <www.ichs.ufop.br/conifes>. Acesso: 20 jun. 2011.

BROSE, Marcus. Descentralização e good government: como aperfeiçoar o desempenho dos governos locais? Revista do Serviço Público, Brasília, v. 53, n. 3, p. 94-138, abr./jun. 2002.

CAIXA ECONÔMICA FEDERAL (CEF). Cartilha PNAFM. Disponível em: < http://downloads.caixa. gov.br/gov/cartilhapnafm.>. Acesso: 24 jun. 2011.

CAIXA ECONÔMICA FEDERAL (CEF). Programa Nacional de Apoio à Gestão Administrativa e Fiscal dos Municípios Brasileiros/Contratos Assinados. Brasília: CEF, 2008.

CORRÊA, Letícia V. Atuação do BNDES nos investimentos na gestão do setor público: estudo do caso Pmat - Santo André (SP). BNDEs Setorial: Setor Público, Rio de Janeiro, n. 30, p. 211-236, 2009.

EVANS, Peter B.; RUESCHMEYER, Dietrich; SKOCPOL, Theda. On the road toward a more understanding of the state. In: EVANS, Peter B.; RUESCHMEYER, Dietrich; SKOCPOL, Theda. Bringing the state back in. Cambridge: Cambridge University Press, 2002. p. 347-366.

GUARNERI, Lucimar da S. (Coord.). Modernização da gestão pública: uma avaliação de experiências inovadoras. Rio de Janeiro: BNDES, 2002.

GUEDES, José R. M. Comentários à Lei de Responsabilidade Fiscal. Rio de Janeiro: Ibam, 2001.

HACKER, Jacob S. The historical logic of national health insurance: structure and sequence in the development of British, Canadian, and US medical policy. Studies in American Political Development, Cambridge, v. 12, n. 1, p. 57-130, Spring 1998.

KINGDON, John W. Agendas, alternatives, and public policies. Nova York: Addison-Wesley Educational Publishers Inc, 1997.

KJAER, Mette; HANSEN, Ole H.; THOMSEN, Jens P. F. Conceptualizing state capacity. 2002. Disponível em: <www.demstar.dk/papers>. Acesso: 16 jun. 2011.

LEAL, Vitor N. Coronelismo, enxada e voto. São Paulo: Alfa-Omega, 1978.

MAHONEY, James; THELEN, Kathleen. Explaining institutional change: ambiguity, agency, and power. Cambridge: Cambridge University Press, 2003. 
MELO, Marcus A. Crise federativa, guerra fiscal e "hobbesianismo municipal": efeitos perversos da descentralização? São Paulo em Perspectiva, São Paulo, v. 10, n. 3, p. 11-20, jul./set. 1996.

MELO, Marcus A. Municipalismo, nation building e a modernização do Estado no Brasil. Revista Brasileira de Ciências Sociais, São Paulo, v. 8, n. 23, p. 85-100, out. 1993.

MINISTÉRIO DA FAZENDA. PNAFM: Avanços introduzidos 2006/2007. In: SEMINÁRIO INTERNACIONAL DE TRIBUTAÇÃO IMOBILIÁRIA, 2007, Salvador. MINISTÉRIO DA FAZENDA. Programa nacional de apoio à gestão administrativa e fiscal dos municípios brasileiros. Brasília: 2002.

MINISTÉRIO DA FAZENDA. Programa Nacional de Apoio à Gestão Administrativa e Fiscal dos Municípios Brasileiros. Relatório de acompanhamento. Brasília: 2006.

MINISTÉRIO DA FAZENDA. Programa Nacional de Apoio à Gestão Administrativa e Fiscal dos Municípios Brasileiros. Relatório de acompanhamento. Brasília: 2010.

MINISTÉRIO DO PLANEJAMENTO. Programa de Estratégia e Plano de Ação para a Efetividade do Desenvolvimento no Brasil (PRODEV). Contratação de consultoria individual. Brasília: Seges, 2010.

PIERSON, Paul. Fragmented welfare states: federal institutions and the development of social policies. Governance: An International Journal of Policy and Administration, v. 8, n. 4, p. 449-478, out. 1995.

PIERSON, Paul. When the effect becomes cause: policy feedback and political change. World Politics, v. 45, n. 4, p. 595-628, jul. 1993.

PRESIDÊNCIA DA REPÚBLICA. Balanço final do governo Lula (livro 6). Brasília, 2010.

PRESIDÊNCIA DA REPÚBLICA. Secretaria de Relações Institucionais. Guia básico para a gestão dos municípios. Brasília, 2008.

RAGIN, Charles C. The comparative method: moving beyond qualitative and quantitative strategies. Califórnia: University California Press, 1987.

REZENDE, Fernando. Planejamento no Brasil: auge, declínio e caminhos para a reconstrução. Brasília: Cepal/Ipea, 2009.

SADDI, Fabiana da C. Política e economia no federalismo do governo Geisel. Revista de Economia Política, v. 23, n. 2 (90), p. 28-46, abr./jun. 2003.

SECRETARIA DE COMUNICAÇÃO SOCIAL DA PRESIDÊNCIA DA REPÚBLICA. Governo federal $e$ municípios. Brasília, 2008.

SKOCPOL, Theda. Bringing the state back in: strategies of analisys in current research. In: EVANS, Peter B.; RUESCHMEYER, Dietrich; SKOCPOL, Theda. Bringing the state back in. Cambridge: Cambridge University Press, 2002. p. 3-41.

SOUZA, Celina. Federalismo, desenho constitucional e instituições federativas no Brasil pós-1988. Revista de Sociologia e Política, n. 24, p. 105-121, jun. 2005. 
THELEN, Kathleen. How institutions evolve: insights from comparative historical analysis. In: MAHONEY, James; RUESCMEYER, Dietrich (Ed.). Comparative historical analysis in the social sciences. Cambridge: Cambridge University Press, 2003. p. 208-240.

TILLY, Charles. Big structures, large process, huge comparisons. Michigan: University of Michigan, 1983.

VIGNOLI, Francisco H. Poder local e a questão municipal. Cadernos FGV Projetos, v. 4, n. 8, p. 1520, 2009.

Eduardo José Grin é cientista político e pesquisador do Centro de Administração Pública e Governo (Ceapg/FGV São Paulo). E-mail: eduardo.grin@fgv.br. 